\title{
Antimicrobial Susceptibility and Sub-MIC Biofilm Formation of Moraxella catarrhalis Clinical Isolates under Anaerobic Conditions
}

\author{
Balbina J. Plotkin*, Thomas Hatakeyama, Zheng Ma \\ Department of Microbiology and Immunology, Midwestern University, Downers Grove, Illinois, USA \\ Email: ${ }^{*}$ bplotk@midwestern.edu
}

Received 13 March 2015; accepted 7 April 2015; published 9 April 2015

Copyright (C) 2015 by authors and Scientific Research Publishing Inc.

This work is licensed under the Creative Commons Attribution International License (CC BY). http://creativecommons.org/licenses/by/4.0/

cC) (7) Open Access

\begin{abstract}
A medium was developed to support the anaerobic growth and antimicrobial susceptibility testing of clinical Moraxella catarrhalis isolates. The MICs of clinical Moraxella catarrhalis isolates under anaerobic conditions were, in general, decreased as compared to atmospheric or capnophilic conditions, while the MBCs for all conditions were within a 2 fold concentration dilution. Biofilm formation was affected by the presence of sub-MIC concentrations of azithromycin and the tested quinolones with the exception of levofloxacin.
\end{abstract}

\section{Keywords}

Anaerobic, Nitrate, Otitis Media, Sinusitis, Pneumonia, Biofilm, Sub-MIC, Anaerobic Respiration, Moraxella catarrhalis

\section{Introduction}

The vast majority of infections (60\% to 80\%) are biofilm associated [1] [2]. Biofilms are comprised of organisms embedded in an extracellular matrix [3]. It is well established that biofilms form an environment that protects its inhabitants from the actions of both host factors and antimicrobials [1] [2] [4]. This protective function of biofilm and its subsequent inhibitory effect on antimicrobial activity is attributed, in part, to the inability of the drug to penetrate the biofilm in concentrations sufficient for activity [4]-[6]. The presence of sub-inhibitory antibiotic concentrations can further exacerbate the situation by enhancing the levels of biofilm formation [7][10]. An additional factor that can contribute to the phenotypic antimicrobial resistance of bacteria in a biofilm is the physiologic status of the organisms, including whether the organism is undergoing aerobic or anaerobic res-

*Corresponding author.

How to cite this paper: Plotkin, B.J., Hatakeyama, T. and Ma, Z. (2015) Antimicrobial Susceptibility and Sub-MIC Biofilm Formation of Moraxella catarrhalis Clinical Isolates under Anaerobic Conditions. Advances in Microbiology, 5, $244-251$. http://dx.doi.org/10.4236/aim.2015.54022 
piration. Growth in reduced oxygen conditions is associated with decreased antimicrobial susceptibility [11]. Thus, bacteria can exhibit de facto increased intrinsic biofilm-associated resistance as a result of the combination of decreased levels of oxygen, and sub-MIC antibiotic levels which further enhances phenotypic resistance [7] [8].

M. catarrhalis is a significant pathogen of the respiratory tract [12]-[14]. In addition to causing sinusitis, acute exacerbation of chronic obstructive pulmonary disease and pneumonia, it is the third most common bacterial cause of otitis media (OM). While long thought of as a strict aerobe, recent studies have shown that laboratory strains of $M$. catarrhalis are capable of anaerobic respiration via the nitrate reductase pathway, a factor that could play a role in treatment failure [15]-[17]. In pneumonia, sinusitis and otitis media (OM), the levels of available oxygen vary depending on the amount of oxygen diffusing from the mucosa and amount of microbial biofilm present [11] [18]. In OM with effusion, the Eustachian tube is hypoxic with the extent of anaerobic areas dependent on the levels of biofilm present [11] [18]. Clinically, treatment failure for OM, as well as sinusitis and other respiratory tract diseases, may be related to altered growth in response to variations in oxygen levels. To date, growth of $M$. catarrhalis clinical isolates under anaerobic conditions has not been studied. In addition, the effect of oxygenation on clinical isolates antimicrobial susceptibility and biofilm formation in response to sub-MICs of antibiotics is not known. The focus of this study was to develop a medium for the anaerobic culture of clinical M. catarrhalis isolates and determine their susceptibility and biofilm formation under various atmospheric conditions.

\section{Materials and Methods}

\subsection{Bacterial Isolates}

Clinical isolates of $M$. catarrhalis $(\mathrm{n}=14)$ were prepared as previously described [19]. The isolates used were kindly provided by J. Tjhio (Loyola University Stritch School of Medicine, Maywood, IL). All isolates tested elaborated a beta-lactamase by nitrocefin assay (data not shown).

\subsection{Development of Media for Anaerobic Growth of Clinical M. catarrhalis Isolates}

All commercial media were prepared per label directions. Supplements were prepared individually, and in combination (as indicated) then filter sterilized (Table 1). For maximal level of achievable growth and generation time, each medium was inoculated with $M$. catarrhalis to a final concentration of $\sim 10^{5} \mathrm{CFU} / \mathrm{ml}$ then incubated $\left(35^{\circ} \mathrm{C}\right)$ aerobically and anaerobically (Whitley Anaerobic Workstation A35). After incubation (48 h), samples were removed for standard viability count (Muller Hinton: MH agar; aerobic conditions). The optimal medium for anaerobic growth was determined after testing five media alone and with seven different supplements, in various combinations.

Table 1. Media with and without supplements tested for their ability to support the anaerobic growth of Moraxella catarrhalis clinical isolates $(\mathrm{n}=14)$.

\begin{tabular}{|c|c|c|c|c|c|c|c|c|c|c|c|c|}
\hline & & \multicolumn{11}{|c|}{ Supplements ${ }^{\mathrm{a}}$} \\
\hline & & A & B & $\mathrm{C}$ & $\mathrm{D}$ & $\mathrm{E}$ & $\mathrm{F}$ & G & & & & \\
\hline $\begin{array}{c}\text { Broth } \\
\text { Medium } \\
\text { with } \mathrm{NaNO}_{3} \\
(10 \mathrm{mM})^{\mathrm{b}}\end{array}$ & $\begin{array}{l}\text { Medium } \\
\text { alone }\end{array}$ & $\mathrm{YNB}^{\mathrm{a}}$ & $\begin{array}{c}\text { BSA } \\
(0.5 \%)^{d}\end{array}$ & $\begin{array}{c}\text { Yeast } \\
\text { Extract } \\
0.10 \%\end{array}$ & $\begin{array}{l}\text { Glycerol } \\
0.20 \%\end{array}$ & $\begin{array}{l}\text { Glucose } \\
0.20 \%\end{array}$ & $\begin{array}{l}\text { Casein } \\
0.10 \%\end{array}$ & $\begin{array}{c}\text { Bovine } \\
\text { Hemoglobin } \\
0.20 \%\end{array}$ & $A-C^{e}$ & A-E & $A-G$ & $\begin{array}{l}\text { Aerobic } \\
\text { Growth }\end{array}$ \\
\hline Muller Hinton & $-{ }^{c}$ & - & - & - & - & - & - & - & - & - & - & $++^{\mathrm{b}}$ \\
\hline $\begin{array}{c}\text { Brain Heart } \\
\text { Infusion (BHI) }\end{array}$ & - & - & - & - & - & - & - & - & - & $+^{\mathrm{f}}$ & ++ & $++^{\mathrm{f}}$ \\
\hline Middlebrook & - & - & - & - & - & - & - & - & - & + & + & $\mathrm{ND}^{\mathrm{g}}$ \\
\hline Brucella & - & - & - & - & - & - & - & - & - & - & - & ND \\
\hline Luria-Bertoni & - & - & - & - & - & - & - & - & - & - & - & ND \\
\hline
\end{tabular}

${ }^{a}$ All media were tested with all combinations of supplements; all supplements were made in yeast nitrogen base medium without amino acids or am-

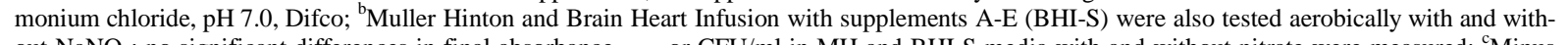
out $\mathrm{NaNO}_{3}$; no significant differences in final absorbance ${ }_{600 \mathrm{~nm}}$ or CFU/ml in $\mathrm{MH}$ and BHI-S media with and without nitrate were measured; ${ }^{\mathrm{c}} \mathrm{Minus}$ sign (-) indicates no growth; plus sign (++) indicates $\sim 1-3 \times 10^{9} \mathrm{CFU} / \mathrm{ml}$; $(+)$ indicates $\sim 1-2 \times 10^{8} \mathrm{CFU} / \mathrm{ml}$; ${ }^{\mathrm{d}}$ Bovine Serum Albumin fraction IV; ${ }^{\mathrm{e}}$ Indicates combination of indicated supplements, e.g. A-C = A, B, C; ${ }^{\mathrm{f}}$ Medium used for anaerobic growth of $M$. catarrhalis for all subsequent experiments; ${ }^{g}$ Not Determined. 


\subsection{Antimicrobial Testing}

The MIC and MBC for antimicrobials used in the treatment of $M$. catarrhalis otitis media, pneumonia and sinusitis were measured using a microdilution method [14] [20]. Each drug was tested in sextuplicate and repeated once (M. catarrhalis, $\mathrm{n}=8 ; 35^{\circ} \mathrm{C}, 48 \mathrm{~h} ; 5 \% \mathrm{CO}_{2}$ in air; normal atmospheric conditions; or anaerobic conditions) [19].

\subsection{Biofilm Formation in Sub-MICs of Antibiotics}

The effect sub-MICs have on $M$. catarrhalis biofilm formation was determined, as previously described, by the simple expedient of emptying, washing and staining the 96 well plate wells after growth in the presence and absence of antibiotics (PBS, 3x wash; crystal violet, stain; absolute ethanol elutant) [21]. Biofilm levels were determined as a measure of crystal violet staining (Beckman EIA reader; Abs $_{540}$ ). The measurements were compared against a control 96 well plate that contained only drug (negative control) or only organisms (positive control). Significance testing was determined by ANOVA, with Tukey post hoc test (GraphPad Software, San Diego, CA).

\section{Results}

\subsection{Development of Medium for Anaerobic Growth of Clinical Isolates}

Previous studies report the growth of laboratory-adapted M. catarrhalis in brain heart infusion medium (BHI) with $10 \mathrm{mM} \mathrm{NaNO}$ [22] [23]. This medium did not support the growth of any $M$. catarrhalis clinical isolates tested $(n=14)$. This was probably because clinical isolates can exhibit growth characteristics that are different from laboratory-adapted strains [24]. Therefore, a requisite first step focused on development of a medium that supported the anaerobic growth of $M$. catarrhalis clinical isolates $(n=14)$ to levels similar to that measured for the isolates' aerobic growth in Mueller Hinton broth, the standard medium used for antibiotic testing (Table 1). Of the media tested, only BHI with supplements A-E (BHI-S) or A-G consistently supported growth of all isolates; the level of anaerobic and aerobic growth was similar to growth measured in $\mathrm{MH}$ incubated aerobically (1 - $\left.3 \times 10^{9} \mathrm{CFU} / \mathrm{ml}\right)$. Middlebrook medium with supplements A-E or A-G also supported the anaerobic growth of M. catarrhalis, but to a lesser extent ( $8 \%$ - 13\% less) than that measured for BHI-S. BHI-S was used for all subsequent determinations of the effects aerobic, capnophilic and anaerobic growth conditions have on antimicrobial susceptibility and biofilm formation.

\subsection{MIC and MBC of Clinical Isolates under Various Levels of Oxygenation}

The anaerobic MIC for all antimicrobials tested ranged from significantly less to within 2 fold dilution of that measured for aerobic and capnophilic conditions (Table 2). Anaerobically grown M. catarrhalis' MICs in the presence of clarithromycin, and the quinolones nalidixic acid and ciprofloxacin were the most sensitive as compared to aerobic/capnophilic growth (31-250; 508-1016; 8-31 fold less MIC, respectively). However, the MBC range for these drugs was within 2 fold dilution for all growth conditions. This pattern of the MBC ranges overlapping regardless of growth conditions vs. the MIC range registering significantly less under anaerobic growth occurred for all compounds with the exception of ceftriaxone where the MBC was 4 fold less than that measured under atmospheric conditions and 2 fold below capnophilic conditions. No discernible pattern of susceptibility was noted for the individual isolates with the exception of $M$. catarrhalis isolate 6 which exhibited the highest MIC and MBC to macrolide-azide drugs clarithromycin and azithromycin under all growth conditions.

\subsection{Biofilm Formation}

Biofilm formation in positive controls (organism alone) was unaffected by the lack of oxygen or increased concentration of $\mathrm{CO}_{2}$ (Table 2). Of the antimicrobials tested, sub-MIC levels of azithromycin and the quinolones, with the exception of levofloxacin, significantly $(p<0.05)$ affected biofilm formation. Nalidixic acid exhibited a bimodal effect on biofilm formation, inhibiting biofilm formation under anaerobic growth conditions while promoting biofilm levels under capnophilic and aerobic conditions. Norfloxacin and ofloxacin increased the biofilm levels under aerobic and capnophilic conditions only. Ciprofloxacin only affected biofilm levels under anaerobic growth (1.8 fold above positive growth control). Azithromycin promoted biofilm formation for one isolate (iso- 
Table 2. Effect of atmospheric air, capnophilic (5\% $\mathrm{CO}_{2}$ in air), and anaerobic environments on Moraxella catarrhalis $(\mathrm{n}=$ 8) response to antibiotics (MIC and MBC) and biofilm formation.

\begin{tabular}{|c|c|c|c|c|c|c|c|}
\hline Antibiotic & $\begin{array}{c}\text { Growth } \\
\text { Condition }^{1}\end{array}$ & $\underset{(\mu \mathrm{g} / \mathrm{ml})}{\mathrm{MIC}}$ & $\begin{array}{c}\text { MBC } \\
(\mu \mathrm{g} / \mathrm{ml})\end{array}$ & $\begin{array}{l}\text { Biofilm } \\
\text { (No. of } \\
\text { Isolates } \\
\text { Affected) }\end{array}$ & $\begin{array}{c}\text { Peak } \\
\text { Biofilm } \\
\text { Level } \\
\text { Abs }_{540}{ }^{2}\end{array}$ & $\begin{array}{c}\text { Drug Concentration }(\mu \mathrm{g} / \mathrm{ml}) \\
\text { at Peak Biofilm Level } \\
\text { (Maximum Drug Concentration }^{3} \\
\text { Affecting Biofilm) }\end{array}$ & $\begin{array}{l}\text { Ratio (Test } \\
\text { Biofilm Level } \\
\text { /Control Biofilm } \\
\text { Level) }{ }^{5}\end{array}$ \\
\hline \multicolumn{8}{|l|}{$\begin{array}{l}\text { Amoxicillin- } \\
\text { clavulanate }^{6}\end{array}$} \\
\hline & Aero & $0.125-2.0$ & $0.125-2.0$ & 0 & $\mathrm{NE}^{4}$ & $\mathrm{NE}$ & $\mathrm{NE}$ \\
\hline & $\mathrm{CO}_{2}$ & $0.125-2.0$ & $0.125-2.0$ & 0 & NE & NE & $\mathrm{NE}$ \\
\hline & Anaero & $0.032-1.0$ & $0.063-1.0$ & 0 & NE & $\mathrm{NE}$ & $\mathrm{NE}$ \\
\hline \multicolumn{8}{|l|}{ Cefaclor $^{7}$} \\
\hline & Aero & $16.0-256.0$ & $16.0-256.0$ & 0 & $\mathrm{NE}$ & $\mathrm{NE}$ & $\mathrm{NE}$ \\
\hline & $\mathrm{CO}_{2}$ & $4.0-64.0$ & $4.0-128.0$ & 0 & $\mathrm{NE}$ & NE & $\mathrm{NE}$ \\
\hline & Anaero & $0.063-32.0$ & $1.0-32.0$ & 0 & $\mathrm{NE}$ & $\mathrm{NE}$ & $\mathrm{NE}$ \\
\hline \multicolumn{8}{|l|}{ Cefdinir $^{7}$} \\
\hline & Aero & $0.5-8.0$ & $0.5-16.0$ & 0 & $\mathrm{NE}$ & $\mathrm{NE}$ & $\mathrm{NE}$ \\
\hline & $\mathrm{CO}_{2}$ & $0.5-4.0$ & $1.0-4.0$ & 0 & NE & $\mathrm{NE}$ & $\mathrm{NE}$ \\
\hline & Anaero & $0.008-1.0$ & $0.25-1.0$ & 0 & $\mathrm{NE}$ & $\mathrm{NE}$ & $\mathrm{NE}$ \\
\hline \multicolumn{8}{|l|}{ Cefixime $^{7}$} \\
\hline & Aero & $0.125-2.0$ & $0.5-4.0$ & 0 & $\mathrm{NE}$ & $\mathrm{NE}$ & $\mathrm{NE}$ \\
\hline & $\mathrm{CO}_{2}$ & $0.125-2.0$ & $0.5-4.0$ & 0 & $\mathrm{NE}$ & $\mathrm{NE}$ & $\mathrm{NE}$ \\
\hline & Anaero & $0.002-0.25$ & $0.125-2.0$ & 0 & $\mathrm{NE}$ & NE & $\mathrm{NE}$ \\
\hline \multicolumn{8}{|l|}{ Ceftriaxone $^{7}$} \\
\hline & Aero & $0.063-4.0$ & $0.063-4.0$ & 0 & $\mathrm{NE}$ & $\mathrm{NE}$ & $\mathrm{NE}$ \\
\hline & $\mathrm{CO}_{2}$ & $0.063-2.0$ & $0.063-2.0$ & 0 & $\mathrm{NE}$ & $\mathrm{NE}$ & $\mathrm{NE}$ \\
\hline & Anaero & $0.063-0.25$ & $0.032-1.0$ & 0 & $\mathrm{NE}$ & $\mathrm{NE}$ & $\mathrm{NE}$ \\
\hline \multicolumn{8}{|l|}{ Cefuroxime $^{7}$} \\
\hline & Aero & $2.0-16.0$ & $2.0-16.0$ & 0 & $\mathrm{NE}$ & $\mathrm{NE}$ & $\mathrm{NE}$ \\
\hline & $\mathrm{CO}_{2}$ & $2.0-16.0$ & $2.0-16.0$ & 0 & $\mathrm{NE}$ & $\mathrm{NE}$ & $\mathrm{NE}$ \\
\hline & Anaero & $0.5-8.0$ & $0.032-1.0$ & 0 & $\mathrm{NE}$ & $\mathrm{NE}$ & $\mathrm{NE}$ \\
\hline \multicolumn{8}{|l|}{ Azithromycin $^{8}$} \\
\hline & Aero & $0.063-0.5$ & $0.125-1.0$ & 0 & $\mathrm{NE}$ & $\mathrm{NE}$ & $\mathrm{NE}$ \\
\hline & $\mathrm{CO}_{2}$ & $0.25-1.0$ & $1.0-2.0$ & 1 & $0.38 \pm 0.002$ & $0.25(0.25)$ & 2.21 \\
\hline & Anaero & $0.004-0.25$ & $0.5-2.0$ & 0 & $\mathrm{NE}$ & $\mathrm{NE}$ & $\mathrm{NE}$ \\
\hline \multicolumn{8}{|c|}{ Clarithromycin ${ }^{8}$} \\
\hline & Aero & $0.5-4.0$ & $0.5-8.0$ & 0 & $\mathrm{NE}$ & $\mathrm{NE}$ & $\mathrm{NE}$ \\
\hline & $\mathrm{CO}_{2}$ & $0.5-4.0$ & $0.5-4.0$ & 0 & $\mathrm{NE}$ & $\mathrm{NE}$ & $\mathrm{NE}$ \\
\hline & Anaero & $0.016-0.016$ & $0.5-4.0$ & 0 & $\mathrm{NE}$ & $\mathrm{NE}$ & $\mathrm{NE}$ \\
\hline
\end{tabular}




\section{Continued}

Nalidixic Acid

$\begin{array}{ccccccr}\text { Aero } & 32.0-64.0 & 32.0-64.0 & 4 & 0.15 \pm 0.001 & 32.0(64.0) & 1.28 \\ \mathrm{CO}_{2} & 32.0-64.0 & 32.0-64.0 & 4 & 0.13 \pm 0.001 & 64.0(64.0) & 1.25 \\ \text { Anaero } & 0.063-0.063 & 16.0-128.0 & 3 & 0.09 \pm 0.002 & 16.0(16.0) & 0.80\end{array}$

Ciprofloxacin $^{9}$

\begin{tabular}{|c|c|c|c|c|c|c|c|}
\hline & Aero & $0.031-0.125$ & $0.031-0.125$ & 0 & $\mathrm{NE}$ & $\mathrm{NE}$ & $\mathrm{NE}$ \\
\hline & $\mathrm{CO}_{2}$ & $0.063-0.125$ & $0.063-0.125$ & 0 & $\mathrm{NE}$ & $\mathrm{NE}$ & $\mathrm{NE}$ \\
\hline & Anaero & $0.004-0.004$ & $0.031-0.25$ & 1 & $0.22 \pm 0.003$ & $1.0(1.0)$ & 1.80 \\
\hline \multicolumn{8}{|l|}{ Norfloxacin $^{9}$} \\
\hline & Aero & $1.0-4.0$ & $2.0-8.0$ & 4 & $0.15 \pm 0.001$ & $0.13(8.0)$ & 1.47 \\
\hline & $\mathrm{CO}_{2}$ & $4.0-8.0$ & $4.0-16.0$ & 3 & $0.16 \pm 0.002$ & $4.0(8.0)$ & 1.51 \\
\hline & Anaero & $0.008-4.0$ & $1.0-8.0$ & 0 & $\mathrm{NE}$ & $\mathrm{NE}$ & $\mathrm{NE}$ \\
\hline \multicolumn{8}{|l|}{ Levofloxacin ${ }^{9}$} \\
\hline & Aero & $0.125-0.25$ & $0.25-0.5$ & 0 & $\mathrm{NE}$ & $\mathrm{NE}$ & $\mathrm{NE}$ \\
\hline & $\mathrm{CO}_{2}$ & $0.125-0.25$ & $0.125-0.5$ & 0 & $\mathrm{NE}$ & $\mathrm{NE}$ & $\mathrm{NE}$ \\
\hline & Anaero & $0.004-0.125$ & $0.125-0.25$ & 0 & $\mathrm{NE}$ & $\mathrm{NE}$ & $\mathrm{NE}$ \\
\hline \multicolumn{8}{|l|}{ Ofloxacin $^{9}$} \\
\hline & Aero & $0.125-0.25$ & $0.125-0.5$ & 4 & $0.21 \pm 0.001$ & $2.0(4.0)$ & 1.60 \\
\hline & $\mathrm{CO}_{2}$ & $0.125-0.25$ & $0.125-0.5$ & 8 & $0.18 \pm 0.003$ & $4.0(4.0)$ & 1.54 \\
\hline & Anaero & $0.004-0.25$ & $0.25-1.0$ & 0 & NE & $\mathrm{NE}$ & $\mathrm{NE}$ \\
\hline
\end{tabular}

$\begin{array}{ll}0 & \mathrm{NE} \\ 0 & \mathrm{NE}\end{array}$

$\begin{array}{ll}\text { NE } & \text { NE } \\ \text { NE } & \text { NE }\end{array}$

late 3; 2.21 fold increase above positive control) to the greatest extent under $5 \% \mathrm{CO}_{2}$ in air. The response of the isolates was highly variable with none responding to more than one of the compounds; isolate 9 biofilm formation was unaffected, regardless of growth condition.

\section{Discussion}

Moraxella catarrhalis is a significant cause of diseases of the upper airways, ear and lungs [12] [17] [25]-[28]. Collectively, these diseases rank as significant causes of morbidity and mortality that are associated with treatment failure [17]. Biofilm formation is linked to varying extents with each of these diseases [2] [4] [5] [28]. To survive in diverse host environments $M$. catarhalis must be able to grow both aerobically and anaerobically. Studies with Neisseria gonorrhoeae and Pseudomonas spp., in model biofilms systems, have shown that biofilms in aerobic environments have areas where the oxygen threshold is sufficiently low that the organism transitions to anaerobic respiration, enabled by the elevated levels of nitrate from oxidation of nitric oxide produced during the inflammatory process [11] [29]-[31]. Although it is known that pathogens growing anaerobically typically exhibit alterations in antimicrobial susceptibility (less susceptible), clinical laboratory testing of most bacteria, including M. catarrhalis, is performed aerobically [32] [33]. With the newly developed medium, the anaerobic MBC measured was similar to that determined either aerobically or in the presence of increased $\mathrm{CO}_{2}$ levels, although the MIC was typically significantly reduced. This indicates that presence or absence of oxygen is not an essential factor dictating $M$. catarrhalis susceptibility. However, the combination of atmospheric environment 
and sub-MIC of antimicrobial can alter M. catarrhalis expression of biofilm.

We are only beginning to understand $M$. catarrhalis biofilms as they relate to antibiotic sub-MICs and microbe physiologic state [22] [23] [34] [35]. To an extent, advancement was hampered by the differences in nutritional requirements of $M$. catarrhalis clinical isolates vs. laboratory-adapted strains. Pharmacodynamic data show that antibiotic sub-MICs occur during the course of treatment [9]. Antibiotic sub-MICs can affect biofilm formation [7] [9]. The effect of the antimicrobials on M. catarrhalis biofilm formation was dependent on the combination of sub-MICs of the antimicrobial, growth condition, and clinical isolate tested, with levels of biofilm formed either enhanced or reduced in comparison to antibiotic-free controls. The study also showed that biofilm formation in response to sub-MICs of antibiotics, particularly with respect to biofilm enhancement by certain quinolones, is isolate dependent, as has been reported for other microbes [7] [9]. The findings in this study of clinical isolate specificity in environmental response may provide an alternative avenue for determining the molecular factors involved with enhanced phenotypic antimicrobial resistance associated with clinical isolates.

In summary, this study reports a novel medium that supports the anaerobic growth of $M$. catarrhalis clinical isolates, and that for anaerobically grown cells the MBC is the best indicator of susceptibility. In addition, the findings herein show that environmental conditions in combination affect elaboration of biofilm in an isolatespecific manner.

\section{Acknowledgements}

This project was supported by Midwestern University Office of Research and Sponsored Programs, Midwestern University Biomedical Sciences Program, and Midwestern University College of Dental Medicine-Illinois.

\section{References}

[1] Costerton, J., Lewandowski, Z., Caldwell, D., Korber, D. and Lappin-Scott, H. (1995) Microbial Biofilms. Annual Review of Microbiology, 49, 711-745. http://dx.doi.org/10.1146/annurev.mi.49.100195.003431

[2] Costerton, J.W., Stewart, P.S. and Greenberg, E.P. (1999) Bacterial Biofilms: A Common Cause of Persistent Infections. Science, 284, 1318-1322. http://dx.doi.org/10.1126/science.284.5418.1318

[3] Gilbert, P., Maira-Litran, T., McBain, A., Rickard, A. and Whyte, F. (2002) The Physiology and Collective Recalcitrance of Microbial Biofilm Communities. Advances in Microbial Physiology, 46, 202-256. http://dx.doi.org/10.1016/S0065-2911(02)46005-5

[4] Dongari-Bagtzoglou, A. (2008) Pathogenesis of Mucosal Biofilm Infections: Challenges and Progress. Expert Review of Anti-Infective Therapy, 6, 201-208. http://dx.doi.org/10.1586/14787210.6.2.201

[5] Lewis, K. (2001) Riddle of Biofilm Resistance. Antimicrob Agents Chemother, 45, 999-1007. http://dx.doi.org/10.1128/AAC.45.4.999-1007.2001

[6] Wise, R., Hart, T., Cars, O., Streulens, M., Helmuth, R., Huovinen, P. and Sprenger, M. (1998) Antimicrobial Resistance. BMJ, 317, 609-610. http://dx.doi.org/10.1136/bmj.317.7159.609

[7] Farzam, F. and Plotkin, B.J. (2001) Effect of Sub-MICs of Antibiotics on the Hydrophobicity and Production of Acidic Polysaccharide by Vibrio vulnificus. Chemotherapy, 47, 184-193. http://dx.doi.org/10.1159/000063220

[8] Pinheiro, L., Brito, C.I., Pereira, V.C., de Oliveira, A., Camargo, C.H. and da Cunha, M. (2014) Reduced Susceptibility to Vancomycin and Biofilm Formation in Methicillin-Resistant Staphylococcus epidermidis Isolated from Blood Cultures. Memórias do Instituto Oswaldo Cruz, 109, 871-878. http://dx.doi.org/10.1590/0074-0276140120

[9] Wojnicz, D. (2007) The Influence of Subinhibitory Concentrations of Antibiotics on the Bacterial Adhesion. Advances in Clinical and Experimental Medicine, 16, 141-148.

[10] Lau, D. and Plotkin, B. (2013) Antimicrobial and Biofilm Effects of Herbs Used in Traditional Chinese Medicine. Natural Product Communications, 8, 1617-1620.

[11] Borriello, G., Werner, E., Roe, F., Kim, A., Ehrlich, G. and Stewart, P. (2004) Oxygen Limitation Contributes to Antibiotic Tolerance of Pseudomonas aeruginosa in Biofilms. Antimicrobial Agents and Chemotherapy, 48, 2659-2664. http://dx.doi.org/10.1128/AAC.48.7.2659-2664.2004

[12] Murphy, T. and Parameswaran, G. (2009) Moraxella catarrhalis, a Human Respiratory Tract Pathogen. Clinical Infectious Diseases, 49, 124-131. http://dx.doi.org/10.1086/599375

[13] Daly, K.A., Hoffman, H.J., Kvaerner, K.J., Casselbrant, M.L., Homoe, P. and Rovers, M.M. (2010) Epidemiology, Natural History, and Risk Factors: Panel Report from the Ninth International Research Conference on Otitis Media. 
International Journal of Pediatric Otorhinolaryngology, 74, 231-240. http://dx.doi.org/10.1016/j.ijporl.2009.09.006

[14] Leibovitz, E., Broides, A., Greenberg, D. and Newman, N. (2010) Current Management of Pediatric Acute Otitis Media. Expert Review of Anti-Infective Therapy, 8, 151-161. http://dx.doi.org/10.1586/eri.09.112

[15] Thornton, R.B., Wiertsema, S.P., Kirkham, L.A.S., Rigby, P.J., Vijayasekaran, S., Coates, H.L. and Richmond, P.C. (2013) Neutrophil Extracellular Traps and Bacterial Biofilms in Middle Ear Effusion of Children with Recurrent Acute Otitis Media-A Potential Treatment Target. PLoS ONE, 8, e53837. http://dx.doi.org/10.1371/journal.pone.0053837

[16] Pelton, S.I. and Leibovitz, E. (2009) Recent Advances in Otitis Media. Pediatric Infectious Disease Journal, 28, S133S137. http://dx.doi.org/10.1097/INF.0b013e3181b6d81a

[17] Parameswaran, G.I. and Murphy, T.F. (2009) Chronic Obstructive Pulmonary Disease. Role of Bacteria and Updated Guide to Antibacterial Selection in the Older Patient. Drugs \& Aging, 26, 985-995. http://dx.doi.org/10.2165/11315700-000000000-00000

[18] Takahashi, M., Niwa, H. and Yanagita, N. (1990) $\mathrm{PO}_{2}$ Levels in Middle Ear Effusions and Middle Ear Mucosa. Acta Oto-Laryngologica, 110, 39-42. http://dx.doi.org/10.3109/00016489009124807

[19] Kostova, M., Myers, C., Beck, T., Plotkin, B., Green, J., Boshoff, H., Barry III, C.E., Deschamps, J. and Konaklieva, M. (2011) C4-Alkylthiols with Activity against Moraxella catarrhalis and Mycobacterium tuberculosis. Bioorganic \& Medicinal Chemistry, 19, 6842-6852. http://dx.doi.org/10.1016/j.bmc.2011.09.030

[20] Brook, I. (2005) Microbiology and Antimicrobial Management of Sinusitis. Journal of Laryngology \& Otology, 119, 251-258. http://dx.doi.org/10.1258/0022215054020304

[21] Kirby, D., Raino, C., Rabor Jr., S.F., Wasson, C. and Plotkin, B. (2012) Semi-Automated Method for Multi-Tasking Measurement of Microbial Growth, Capsule, and Biofilm Formation. Advances in Microbiology, 2, 623-628. http://dx.doi.org/10.4236/aim.2012.24081

[22] Wang, W., Kinkel, T., Martens-Habbena, W., Stahl, D.A., Fang, F.C. and Hansen, E.J. (2011) The Moraxella catarrhalis Nitric Oxide Reductase Is Essential for Nitric Oxide Detoxification. Journal of Bacteriology, 193, $2804-2813$. http://dx.doi.org/10.1128/JB.00139-11

[23] Wang, W., Reitzer, L., Rasko, D., Pearson, M., Blick, R., Laurence, C. and Hansen, E. (2007) Metabolic Analysis of Moraxella catarrhalis and the Effect of Selected in Vitro Growth Conditions on Global Gene Expression. Infection and Immunity, 75, 4959-4971. http://dx.doi.org/10.1128/IAI.00073-07

[24] Fux, C., Shirtliff, M., Stoodley, P. and Costerton, J. (2005) Can Laboratory Reference Strains Mirror "Real-World” Pathogenesis? Trends in Microbiology, 13, 58-63. http://dx.doi.org/10.1016/j.tim.2004.11.001

[25] Brook, I. (2006) Bacteriology of Chronic Sinusitis and Acute Exacerbation of Chronic Sinusitis. JAMA Otolaryngology-Head \& Neck Surgery, 132, 1099-1101. http://dx.doi.org/10.1001/archotol.132.10.1099

[26] Hoban, D.J., Doern, G.V., Fluit, A.C., Roussel-Delvallez, M. and Jones, R.N. (2001) Worldwide Prevalence of Antimicrobial Resistance in Streptococcus pneumoniae, Haemophilus influenzae, and Moraxella catarrhalis in the SENTRY Antimicrobial Surveillance Program, 1997-1999. Clinical Infectious Diseases, 32, S81-S93. http://dx.doi.org/10.1086/320181

[27] Manfredi, R., Nanetti, A., Valentini, R. and Chiodo, F. (2000) Moraxella catarrhalis Pneumonia during HIV Disease. Journal of Chemotherapy, 12, 406-411. http://dx.doi.org/10.1179/joc.2000.12.5.406

[28] Marchisio, P., Ghisalberti, E., Fusi, M., Baggi, E., Ragazzi, M. and Dusi, E. (2007) Paranasal Sinuses and Middle Ear Infections: What Do They Have in Common? Pediatric Allergy and Immunology, 18, 31-34. http://dx.doi.org/10.1111/j.1399-3038.2007.00630.x

[29] Falsetta, M., Steichen, C., McEwan, A., Cho, C., Ketterer, M., Shao, J., Hunt, J., Jennings, M. and Apicella, M. (2011) The Composition and Metabolic Phenotype of Neisseria gonorrhoeae Biofilms. Frontiers in Microbiology, 2, 75. http://dx.doi.org/10.3389/fmicb.2011.00075

[30] Kofoed, M., Nielsen, D., Revsbech, N. and Schramm, A. (2012) Fluorescence in Situ Hybridization (FISH) Detection of Nitrite Reductase Transcripts (nirS mRNA) in Pseudomonas stutzeri Biofilms Relative to a Microscale Oxygen Gradient. Systematic and Applied Microbiology, 35, 513-517. http://dx.doi.org/10.1016/j.syapm.2011.12.001

[31] John, E., Russell, P., Nam, B., Jinn, T. and Jung, T. (2001) Concentration of Nitric Oxide Metabolites in Middle Ear Effusion. International Journal of Pediatric Otorhinolaryngology, 60, 55-58. http://dx.doi.org/10.1016/S0165-5876(01)00509-2

[32] Hamad, M., Austin, C., Stewart, A., Higgins, M., Vázquez-Torres, A. and Voskuil, M. (2011) Adaptation and Antibiotic Tolerance of Anaerobic Burkholderia pseudomallei. Antimicrobial Agents and Chemotherapy, 55, 3313-3323. http://dx.doi.org/10.1128/AAC.00953-10

[33] Clinical and Laboratory Standards Institute, Methods for Dilution Antimicrobial Susceptibility Tests for Bacteria that Grow Aerobically; Approved Standard. M07-A8. 2009. 
[34] Hoopman, T.C., Liu, W., Joslin, S.N., Pybus, C., Sedillo, J.L., Labandeira-Rey, M., Laurence, C.A., Wang, W., Richardson, J.A., Bakaletz, L.O. and Hansen, E.J. (2012) Use of the Chinchilla Model for Nasopharyngeal Colonization to Study Gene Expression by Moraxella catarrhalis. Infection and Immunity, 80, 982-995. http://dx.doi.org/10.1128/IAI.05918-11

[35] Pearson, M., Laurence, C., Guinn, S. and Hansen, E. (2006) Biofilm Formation by Moraxella catarrhalis in Vitro: Roles of the UspA1 Adhesin and the Hag Hemagglutinin. Infection and Immunity, 74, 1588-1596. http://dx.doi.org/10.1128/IAI.74.3.1588-1596.2006 